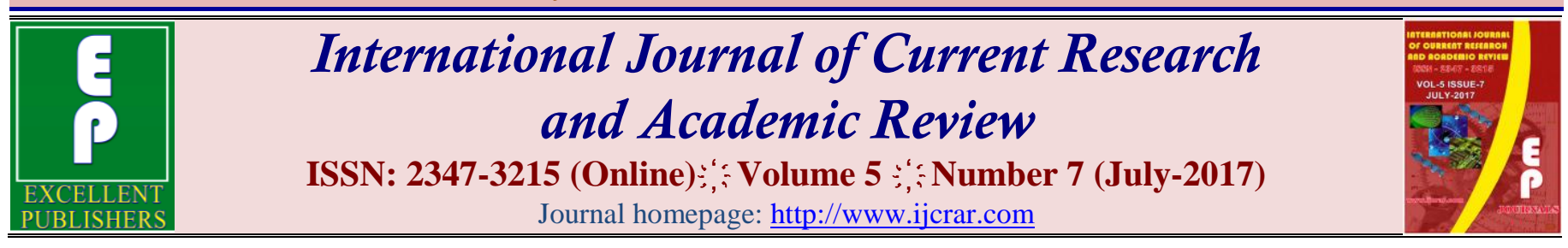

doi: https://doi.org/10.20546/ijcrar.2017.507.002

\title{
Quality of Life, Self Esteem and Self Efficacy among Employed and Unemployed Women
}

\author{
Sajeeth Kumar Gopalakrishnan* and Anuja Venkatesh
}

Department of Psychology, Annamalai University, Tamil Nadu, India

*Corresponding author

\section{Abstract}

The present study is to find out the relationship between Quality of life, Self-esteem and Self efficacy among Employed and Unemployed Women. A Sample of 70 women's (35 employed and 35 unemployed) selected from Chennai. A purposive sampling technique was employed to select the samples. Measure of WHOQOL-100 quality of life assessment was developed by the WHOQOL Group, general selfefficacy scale developed by Jerusalem and Sphwarzer (1979) and self-esteem questionnaire was constructed and standardized by Rosenberg's (1965). Statistical methods like t- test, and correlation analysis were used to analyze the data. The result indicates that a woman with high quality of life shows high self-esteem and selfefficacy.
\end{abstract}

\section{Article Info}

Accepted: 02 July 2017

Available Online: 20 July 2017

\section{Keywords}

Quality of life,

Self-efficacy,

Self-esteem, and

Women

\section{Introduction}

In the wake of rapid social change in various aspects of Indian society, the role and position of women are undergoing changes at a rapid pace. Many women are employed and manage both marital life and career. They take up nontraditional roles and have developed a new outlook of life. These days, women have become more conscious of their own identity and status. Modern women know their self-worth and they wish to develop self-reliance and self-esteem by taking up jobs in various aspects. World Health Organization considers "health" as a state wherein a person is healthy regarding psychological, affective and social aspects and there cannot be observed any kind of disease and psychoneurosis (cited from Saxena and Oconnell, 2002). The above definition implies that in order to assess the health, just the traditional indices of the rate of mortality" and "morbidity" should not be taken into account (Saxena and Oconnell, 2002). In quality of life theory among personal apt features of dissatisfaction from the life or vulnerabilities are low self-esteem and low self-efficacy (Frisch, 2006 :33) and the feeling of laggardness and stagnancy in valuable domains of life (Frisch, 2007:18) and not actually having the achievement motivation. Self-esteem is the degree of value a person considers for himself (Weare, 2000) selfefficacy includes the person's strict belief to successfully perform the required specific behavior to get to the interested result (Bandura, 1997). The achievement motivation is defined as the personal attempt to get to the goals in his/her social milieu (Elliot and Church, 1997). It was such proposed that the self-esteem, skill, the feeling of control and self-efficacy are important adjusting and predicting factors in life quality (Hansson, Middelboe, Mernider, Bjarnason, 1999; Barry and Zissis, 1997; Kentros, Terkelson Hull, Smith and Goodman, 1997). Self-esteem is within the most significant aspects of personality and it determines behavioral features (Sadrossadat, 2000) as well as human's development, as 
most of the specialists assume it an important and basic factor in affective and social adjustment (Lee, 1994). Irandokht Asadi Sadeghi Azar, Promila Vasudeva, Abdolghani Abdollahi (2006) studired the relationship between Quality of Life, Hardiness, Self-efficacy and Self-esteem amongst Employed and Unemployed Married Women in Zabol. Examining the interrelationship between quality of life, hardiness, selfefficacy and self-esteem among working (professional and non-professional), and non-working married women has motivated the researcher to launch this study.

The samples in the present study consisted of 250 married employed women and 250 married unemployed women in the age range of 24-41 years old belonging to lower, middle, and upper socioeconomic status groups, with educational qualification of $10 \pm 2$ and above and having at least one school child. Stratified convenience sampling technique was used for the selection of the sample.

The World Health Organization -Quality of Life (WHO QOL) - BREF, the Personal View Survey (PVS), the General Self-Efficacy Scale (GSE), The Coopersmith Self-Esteem Inventory (CSEI) and demographic questionnaire Sheet were chosen for collection of the data. Obtained Pearson $r$ values revealed significant positive interrelationship between quality of life, hardiness, self-efficacy, and self-esteem in the whole sample, within the subgroups of professional and nonprofessional employed and unemployed women. Obtained Pearson $r$ values revealed significant negative relationship between employment and the above variables in women. It indicates that women with higher quality of life score rank also higher on hardiness, selfefficacy, and self-esteem and vice versa.

\section{Materials and Methods}

\section{Problem}

The aim of the present study is to find out the relationship between Quality of life, Self-esteem and Self efficacy among employed and unemployed women.

\section{Objectives}

To find out the difference between employed and unemployed women in their quality of life, self-esteem and self-efficacy.

To find out the relationship between quality of life, selfesteem and self-efficacy.

\section{Hypothesis}

1. There will be no significant difference between employed and unemployed women in their quality of life, self-esteem and self-efficacy.

2. There will be a significant relationship between quality of life, self-esteem and self-efficacy.

\section{Tool used}

\section{Questionnaire: I}

The World Health Organization -Quality of Life (WHO QOL) - BREF: was chosen to measure the quality of life.

The questionnaire has been developed by world health organization group in order to provide a short form for quality of life assessment that looks at the domain level profiles.

It is an abbreviated 26 items assessment and contains 2 items from the overall QOL and general health, and one item from each of the 24 facets included in WHO QOL100 to provide broad and comprehensive assessment. Each item is rated on a five point scale.

\section{Questionnaire: II}

Rosenberg's 10 item scale is scored through Likert scale, which is one of high fame instrument to assess internal aspects of self-esteem (Nosek et al., 2003). Blascovich and Tomaka (1991) in reviewing the studies printed in case of self-esteem perceived that in $25 \%$ of these studies, Rosenberg's self-esteem scale was applied.

\section{Questionnaire: III}

The General Self-Efficacy Scale (GSE): The scale in German Language was developed in 1979 by Jerusalem and Schwarzer. The scale has 10 items with 4 point scale, ranging from 1 to 4 (1=not at all true), (2=hardly true), ( $3=$ moderately true), to ( $4=$ exactly true).

\section{Samples}

The samples for the present study were "employed and unemployed women" from Chennai. Data was collected from 70 women's. Among them 35 were employed and 35 were unemployed women. Purposive sampling method was employed. Statistical method which is used for the research is t- test and correlation was used in the present study to test the hypothesis and interpret the data. 


\section{Results and Discussion}

Table 1 It is observed from the above table that the mean quality of life value of employed women is 121.09 , while mean quality of life value of unemployed women is 74.00. The calculated ' $t$ '-value is found 13.00 , which is significant at 0.01 level. It is observed from the above table that the mean self-esteem value of employed women is 5.05 , while mean value unemployed women is 3.74. The calculated ' $t$ '-value is found 9.056, which is significant at 0.01 level. And the self-efficacy mean value of employed women is 3.787 , while mean value of unemployed women is 2.984 . The calculated ' $t$ '-value is 16.37, which is significant at 0.01 level. Hence, the hypothesis is not accepted for Quality of life, Self-esteem and Self-efficacy.

Table.1 Mean, std, and t-ratio of employed and unemployed women on Quality of life, Self-esteem and Self-efficacy

\begin{tabular}{llcccc}
\hline Variables & Group & N & MEAN & S.D & 't' \\
\hline Quality of life & Employed & 35 & 121.09 & 16.89 & \multirow{2}{*}{$13.00^{*}$} \\
& Un Employed & 35 & 74.00 & 13.13 & \\
Self esteem & Employed & 35 & 23.83 & 5.05 & \multirow{2}{*}{$9.056^{*}$} \\
& Un Employed & 35 & 14.00 & 3.74 & \\
Self -efficacy & Employed & 35 & 34.54 & 3.787 & \multirow{2}{*}{$16.37^{*}$} \\
& Un Employed & 35 & 21.20 & 2.984 & \\
\hline
\end{tabular}

$*$ Significant at 0.01 level

Table.2 Correlation between quality of life, self-esteem and self-efficacy

\begin{tabular}{|c|c|c|c|}
\hline Variables & Quality of life & Self esteem & Self-efficacy \\
\hline \multicolumn{4}{|l|}{ Quality of life } \\
\hline & $.657^{* *}$ & - & \\
\hline \multicolumn{4}{|l|}{ Self esteem } \\
\hline & $.740^{* *}$ & $.694^{* *}$ & - \\
\hline Self-efficacy & & & \\
\hline
\end{tabular}

The table 2 indicates that there is positive correlation between quality of life, self-esteem and self-efficacy on employed and unemployed women. Hence there is a significant relationship between quality of life, selfesteem and self-efficacy.

1. The employed women have good quality of life, more self-esteem and high self-efficacy than the unemployed women.

2. There is a significant relationship between quality of life, self-esteem and self-efficacy.

From the present study it shows that the correlation between self-esteem and quality of life may be due to high level of self-esteem are more likely to be satisfied with their lives than those with low self-esteem. The present finding supports the notion that self-esteem helps surmount negative experiences and leads to its success. Such success, in turn, helps the individual to experience good things in life. A positive relationship between selfefficacy and quality of life is understandable as people with high on self-efficacy have coping skills to handle stressful situations and they have "I can do it" attitude.

\section{References}

Bandura, A., 1997. Self-efficacy: The exercise of control. Freeman, New York.

Frisch, M.B., 2006. Quality of life of therapy: Applying life satisfaction approach to positive psychology and cognitive therapy. John Wiley and Sons, New Jersey.

Hansson, L., Middelboe, T., Mernider, L., and Bjarnason, O. 1999. Predictor of subjective quality of life in schizophrenic patient living in community. A Nordic multicentre study. The International Journal of Psychiatry, 45, 247-258. 
Saxena, S., and O'Connell, K. 2002. A commentary cross-cultural quality of life assessment at the end of life. Gemologist, 42, 81-85.

Weare, K., 2000. Promoting mental and social health: a whole school approach. Routledge, London.

Irandokht Asadi Sadeghi Azar, Promila Vasudeva, Abdolghani Abdollahi. 2006. Relationship between
Quality of Life, Hardiness, Self-efficacy and Self-esteem amongst Employed and Unemployed Married Women in Zabol. Archive of SID Quality of life, Hardiness, Selfefficacy and Self-esteem in Women. Iranian $J$ Psychiatry, 1:3.

\section{How to cite this article:}

Sajeeth Kumar Gopalakrishnan and Anuja Venkatesh. 2017. Quality of Life, Self Esteem and Self Efficacy among Employed and Unemployed Women. Int.J.Curr.Res.Aca.Rev. 5(7), 10-13.

doi: https://doi.org/10.20546/ijcrar.2017.507.002 